\title{
TEORIA E PRÁTICA POR UM PROJETO DE TRADUÇÃO ESTRANGEIRIZANTE
}

\author{
कर्ष \\ WANessa Gonçalves SiLVA
}

Resumo: O presente artigo traz ao longo de suas páginas parte de uma pesquisa de mestrado intitulada Por um Projeto de Tradução Estrangeirizante: Dr. Faustus, uma tradução comentada e anotada (2006), cujo principal objetivo foi verificar como algumas teorias da tradução poderiam contribuir para a prática tradutória de textos literários, e apresenta um projeto estrangeirizante que conta com a tradução de The tragical history of Doctor Faustus, de Christopher Marlowe, como instrumento de reflexão acerca dos conceitos tradutológicos discutidos. Expõe-se aqui, de forma breve, as teorias abordadas e exemplos de como estas foram aplicadas à prática, extraídos da tradução para o português da obra de Marlowe.

Palavras-chave: Estudos da tradução. Estrangeirização. Berman. Venuti. Schleiermacher. Marlowe.

\begin{abstract}
This article brings forth its pages part of a master degree research named Por um Projeto de Tradução Estrangeirizante: Dr. Faustus, uma tradução comentada e anotada (2006), which aimed at verifying how some translation theories could contribute to the literary texts translation practice. It concerns a foreignizing project that includes the Christopher Marlowe's The tragical history of Doctor Faustus translation as an instrument of reflection about the traductological concepts discussed here. It is briefly presented here the approached theories and examples from Marlowe's piece translation into Portuguese on how these theories were applied to practice.
\end{abstract}

Keywords: Translation Studies. Foreignizing. Berman. Venuti. Schleiermacher. Marlowe.

$\mathrm{N}$

ão é de hoje que discussões em torno dos aspectos teóricos da tradução permeiam a sua prática. Entretanto, foi apenas na década de 70, com o trabalho de Holmes ${ }^{1}$, que os Estudos da tradução começaram a ser considerados uma disciplina. A partir de então, as reflexões sobre as questões teóricas da tradução expandiram-se e diversas linhas de pensamentos tradutológicos delinearam-se, tornando-se ramos teóricos sistematizados, que oferecem ao tradutor estratégias de tradução ou configuram-se como vertentes essencialmente filosóficas.

\footnotetext{
${ }^{1}$ Holmes, J. (1988). The name and nature of Translation Studies. Amsterdam: Rodopi.
} 
No Brasil, o que podemos perceber é um movimento de análise dos estudos realizados por teóricos da tradução, sejam eles contemporâneos ou não; um "mapeamento" e descrição dos tipos de pesquisas acadêmicas realizadas em tradução ${ }^{2}$ e algumas tentativas, que por vezes adquirem dimensões de crítica, de identificar ou apontar traços de teorias da tradução existentes em textos já traduzidos. Por meio dessas tentativas, os estudiosos da tradução discutem a que tipo de teoria, na maioria das vezes inconscientemente, o tradutor recorreu durante a concretização de seu trabalho. Com exceção de alguns projetos de tradução ${ }^{3}$ que prezam pela transmissão de informações intra e extra-textuais referentes ao texto original e a questões ligadas à sua tradução (via prefácios, introduções, comentários ou notas-de-rodapé) pouco ainda tem sido feito, no Brasil, a respeito da utilização consciente de teorias durante o processo tradutório de textos literários.

Sendo esse o pano de fundo, o presente artigo traz em suas linhas um panorama de uma pesquisa acadêmica ${ }^{4}$ iniciada pelo questionamento acerca da relevância das teorias da tradução quando diretamente aplicadas à prática. Assim, verificar em que medida algumas propostas teóricas tradutológicas poderiam funcionar como fundamentação para a prática tradutória de textos literários caracterizou-se como o principal objetivo de um projeto que contou com a tradução do inglês para o português da obra teatral The tragical history of Doctor Faustus (1604) ${ }^{5}$, de Christopher Marlowe, como instrumento de reflexão sobre a utilização de alguns conceitos tradutológicos.

Como não poderia deixar de ser, os conceitos teóricos nos quais a pesquisa foi alicerçada estão diretamente ligados à tradução literária, tendo sido formulados pelos teóricos Antoine Berman (1985/1999; 1995; 2002) e Lawrence Venuti (1995; 2002). Trata-se dos conceitos de etnocentrismo, analítica da tradução e sistemática da deformação (Berman), e reflexões acerca da invisibilidade do tradutor (Venuti). Ainda faço uso das reflexões tradutológicas de Friedrich Schleiermacher (1813/2011 ${ }^{6}$ ) e Henri Meschonnic (1973), e das considerações voltadas exclusivamente para a tradução de textos teatrais, dos estudiosos Patrice Pavis (1995) e José Roberto O’Shea (2002).

\footnotetext{
2 Trata-se do "mapeamento" dos estudos sobre tradução realizados no Brasil nas décadas de 1980 e 1990, feito com base no levantamento realizado pelo Grupo de Trabalho de Tradução da Anpoll - GT de tradução, biênio 2000-2002. Ver: PAGANO \& VASCONCELLOS. "Estudos da tradução no Brasil: reflexões sobre teses e dissertações elaboradas por pesquisadores brasileiros nas décadas de 1980 e 1990”. DELTA, São Paulo, v. 19, n. spe, 2003. Disponível em:

$<$ http://www.scielo.br/scielo.php?script=sci_arttext\&pid=S010244502003000300003\&lng=en\& nrm=iso $>$ Acesso em: 23 out. 2006.

${ }^{3}$ Refiro-me, por exemplo, ao trabalho realizado pelo Prof. Dr. José Roberto O'Shea (UFSC), com o apoio do CNPQ, cujo objetivo é produzir traduções anotadas das obras de William Shakespeare, e, também, a algumas pesquisas de mestrado que visam produzir traduções comentadas e/ou anotadas, como, por exemplo, os trabalhos de Rogério do Amaral (UNESP, 2004) e Maria Paula Gurgel Ribeiro (USP, 2001). No contexto internacional, o trabalho de Robert Bly (1984) pode ser considerado um clássico exemplo de tradução comentada.

4 Pesquisa realizada sob orientação do Prof. Dr. Mauri Furlan, na Universidade Federal de Santa Catarina, com apoio CAPES, e intitulada Por um Projeto de Tradução Estrangeirizante: Dr. Faustus, uma tradução comentada e anotada (2006). Tal dissertação encontra-se, na íntegra, no endereço $<$ http://www.pget.ufsc.br/curso/teses_e_dissertacoes.php> .

${ }^{5}$ Data da primeira publicação do texto. Tradução realizada a partir da edição de J.B. Steane publicada pela Penguin Books em 1969.

${ }^{6}$ Utilizo, neste artigo, a tradução ao português realizada por Mauri Furlan, publicada em 2011.
} 
As noções de etnocentrismo e não-etnocentrismo cunhadas por Berman são, algumas vezes, por mim abordadas, respectivamente, como domesticação e estrangeirização, por serem termos utilizados por Venuti e, a priori, indiretamente estabelecidos por Schleiermacher, quando ele nos fala que, na tradução, o tradutor possui duas opções: ou ele "deixa o autor o mais possível em paz e leva o leitor ao seu encontro" ou "deixa o leitor o mais possível em paz e leva o autor ao seu encontro" (Schleiermacher, 1813/2011, p.22). Embora possuam projetos diferentes e estejam situados em contextos históricos, culturais e políticos distintos, Schleiermacher, Berman e Venuti optam por não "incomodarem" o autor e conduzirem o leitor até ele, sendo essa reflexão acerca da prática tradutória um dos pontos de partida para a elaboração das teorias dos dois contemporâneos.

$\mathrm{O}$ conceito não-etnocêntrico ou estrangeirizante baseia-se num posicionamento ideológico existente na reflexão dos teóricos aqui abordados, ou seja, na intenção de agregar, por meio da tradução, valores culturais estrangeiros a suas próprias culturas, visando ao seu enriquecimento, e de desvencilhar o tradutor de sua condição oculta e ancilar. Assim, ao re-escrever o texto de Marlowe em português, posiciono-me não só como tradutora, mas também como sua autora, pois deixo evidente ao meu leitor o fato de a tradução de The tragical history ter se concretizado a partir de minhas escolhas e de minha escrita.

Deixar à mostra o caráter autoral de uma tradução não significa, porém, desrespeitar o autor do original, fazendo inserções em sua obra ou conferindo a ela um estilo distinto daquele em que foi escrita, por exemplo. Significa, antes, deixar claro à cultura receptora a existência do tradutor e a origem estrangeira do texto. Trata-se de uma relação mútua de respeito entre autor, tradutor e leitor.

\section{As teorias da tradução}

O caminho teórico tradutológico tomado inicia-se no século XIX, na Alemanha romântica, quando Friedrich Schleiermacher, em seu discurso Dos diferentes métodos de traduzir ${ }^{7}$, conduz seus ouvintes a uma intensa reflexão acerca do traduzir e de suas implicações na vida cultural de uma sociedade.

Para Schleiermacher, "o livre e próprio poder combinatório do autor" em conjunto com o "espírito da língua com seu sistema de compreensão e de sombreamento das disposições da alma" (Ibid., p. 09) são essenciais nas obras intelectuais. Então, para que essa interação ocorra, é necessário que o tradutor tenha sensibilidade, habilidades e conhecimento do autor e de sua língua. É nessa relação que o tradutor torna-se capaz de proporcionar o encontro entre seu autor e seu leitor. E existem somente duas maneiras disso acontecer: conduzindo o leitor ao encontro do autor ou levando o autor até seu leitor.

Realizar uma tradução de acordo com o primeiro método, levar o leitor até o autor, significa transmitir ao leitor um texto que não é próprio de sua cultura, isto é, sem negar-lhe o caráter estrangeiro da obra. Trata-se de reescrever a obra original a partir do entendimento que dela o tradutor possui como leitor, "mantendo" a escrita do autor original como ele a deixou em sua própria língua e tornando-a compreensível ao leitor da tradução, sem fazê-lo esquecer-se da nacionalidade do texto em suas mãos.

\footnotetext{
${ }^{7}$ Título original, Über die verschiedenen Methoden des Übersetzens.
} 
Quanto ao segundo método, "levar o autor até o leitor", ao usá-lo o tradutor pretende transpor um texto para a sua língua materna como se nesta o autor estrangeiro o tivesse escrito. $\mathrm{O}$ tradutor molda a obra estrangeira ao estilo das obras produzidas originalmente na cultura dele e não torna perceptível ao seu leitor a real nacionalidade do texto.

Frente a essas duas possibilidades de tradução e ao desejo de fortalecer a língua alemã, assim como resistir à dominação cultural francesa que ameaçava a Alemanha da época, Schleiermacher nos diz, ao longo de seu discurso, ser o primeiro método, além de o mais respeitoso e honesto, o mais apropriado ao desenvolvimento e fortalecimento de uma língua. Ela "somente pode prosperar viçosa e desenvolver plenamente sua força própria mediante o contato multifacetado com o estrangeiro" (Ibid., p. 65-66). Proporcionar esse "contato" e a apreciação de obras estrangeiras, com o auxílio da língua doméstica, somente será possível por meio do trabalho consciente de tradução, ou seja, da tradução que leva o leitor até o autor.

Caminhamos ao longo do século XIX até o XX em companhia de Schleiermacher, para encontrarmos, em 1973, Henry Meschonnic e sua Pour la poétique II: épistémologie de l'écriture, poétique de la traduction, na qual temos alguns princípios teóricos sistematizados acerca da prática tradutória, apresentados sob forma de proposições.

Meschonnic considera o traduzir "uma atividade translinguística tal qual a atividade de escritura de um texto ${ }^{8,}(1973$, p. 306$)$, que parte de determinado escrito, em determinada língua, e gera, em outra língua, não um reflexo do primeiro texto, mas um novo texto, "a tradução-texto", que ganha vida nessa nova cultura, de forma independente. Não se trata da negação da existência do texto original, e sim do reconhecimento da tradução como fato autônomo dentro da cultura receptora, capaz de influenciar a língua e os costumes de seus leitores. Por esse motivo, tradução e texto original são vistos a partir de níveis paralelos e a oposição existente entre traduzir e escrever torna-se vã. Assim, se traduzir e escrever são atividades paralelas, tradutor e autor, ao realizarem seus ofícios, podem ser considerados sob o aspecto do criador.

A relação entre original e tradução, geradora de uma "tradução-texto", é o que Meschonnic considera como descentramento, o resultado de um diálogo entre duas culturas diferentes, que ganha a forma de texto inserido no sistema linguístico da cultura receptora e constitui-se como um sistema textual independente daquele que lhe deu origem, ao mesmo tempo em que se funde a esse (Ibid., p. 320).

A tradução-texto não nega a existência de um texto primeiro, mas sim realiza um movimento de "saída do centro" do sistema linguístico e cultural de uma enunciação para re-enunciá-la em outro sistema linguístico. Além disso, transmite a essa realidade informações que lhe podem ser úteis e contribui para o enriquecimento dessa língua-cultura, tornando tal processo fecundo e conferindo ao tradutor e à tradução um importante papel social.

Em suma, tal qual o ato da escrita, Meschonnic considera a tradução uma atividade translinguística resultante de uma interação entre culturas distintas. Para Schleiermacher, em seu discurso estrangeirizante, uma tradução consciente e responsável deixa mostras de sua origem e fortalece a língua que a aco-

8 “une activité translinguistique comme l'activité d'écriture même d'un texte”. Minha tradução. 
lhe. Assim, a aliança entre esses autores constitui, para mim, uma base teórica sólida, porém não completa. Na busca pela complementaridade, os pensamentos de Schleiermacher e Meschonnic conduziram-me às reflexões de Antoine Berman e Lawrence Venuti. A partir daí, a pesquisa por mim realizada começou a ganhar uma forma mais definida.

Em Pour une critique des traductions: John Donne ${ }^{9}$ (1995), Berman esboça um método para a análise crítica de traduções literárias e deixa evidente três fatores implicados na realização do ofício do tradutor, muito embora, na maioria das vezes, eles não sejam verbalizados: a posição tradutiva, ou a relação existente entre a conscientização do tradutor quanto à "pulsão do traduzir" que lhe é inerente, o ato tradutório e o modo como ele internalizou as normas do traduzir; o projeto de tradução, determinado pela posição tradutiva e pelas necessidades que a obra a traduzir impõe, o que delimita a ação do tradutor e expõe a maneira pela qual ele vai efetuar a tradução; e o horizonte tradutivo, que "explica" o modo como um tradutor realiza o seu trabalho, dentro de certo contexto, ao mesmo tempo em que delimita a sua ação.

Berman (Ibid.) diz que os três fatores acontecem de modo vinculado, embora de forma não linear, podendo, no momento da análise, o horizonte tradutivo ser considerado primeiro. A posição tradutiva e o projeto de tradução dificilmente podem ser considerados independentemente, já que o limite entre esse dois momentos é muito tênue. Embora tais processos sejam descritos por Berman com o objetivo de auxiliar na formação de uma crítica de tradução mais coerente, faço uso de tais conceitos com a intenção de nomear e deixar claro minhas atitudes como tradutora de Marlowe.

Assim, a partir de um horizonte constituído por uma tradição etnocêntrica de tradução, na qual a presença do tradutor é algo praticamente imperceptível, minha posição tradutiva diante do The tragical history consiste em realizar uma retradução do texto de Marlowe com base nas reflexões dos estudiosos aqui apresentados. Como fonte de pesquisa terminológica, sirvo-me de duas traduções ao português da referida obra. Uma de João Duarte Ferreira e Valdemar Azevedo Ferreira, e outra de Alexandre Weller Maar, ambas de 2003. On traduit avec des livres ${ }^{10}$ (Ibid.), como pontua Berman.

O projeto de tradução do The tragical history surgiu a partir do desejo de transmitir o estrangeiro aos que a ele não têm acesso. Trata-se de um projeto declaradamente estrangeirizante, que visa também defender e demonstrar o traduzir como expressão autoral. Por isso, coloco-me diante da obra de Marlowe como tradutora-autora, sempre respeitando a escrita que me serve de marco inicial e a identidade cultural de meu leitor. Resumidamente, tracei um projeto de tradução cujo objetivo central é a transmissão do estrangeiro à cultura doméstica.

Ao propor uma analítica da tradução que permite examinar as alterações encontradas na prosa literária, em La traduction et la lettre ou l'auberge du lointain $^{11}$ (1985/ 1999), Berman apresenta um conjunto de tendências deforma-

\footnotetext{
${ }^{9}$ Data da publicação na França. As citações referentes a esse trabalho foram traduzidas, do francês ao português, por Marlova Assef. Tal obra ainda não foi publicada no Brasil.

10 "Traduz-se com livros".

${ }^{11}$ As citações referentes a esse trabalho foram traduzidas, do francês para o português, por Andréia Guerini, Marie-Hélène Catherine Torres e Mauri Furlan. Durante minha pesquisa, fiz uso do texto em português desses tradutores-autores que ainda não havia sido publicado no Brasil.
} 
doras responsáveis pela formação de "un tout systématique, dont la fin est la destruction, non moins systématique, de la lettre des originaux, au seul profit du " sens» et de la «belle forme "" (Berman, 1985/ 1999, p. 52). Tal analítica propõe-se a desvendar onde agem as tendências deformadoras "qui dévient la traduction de sa pure visée" "13 (Ibid., p. 49). O verdadeiro objetivo da tradução, segundo ele, consiste em permitir a "relação com o Outro, fecundar o Próprio pela mediação do Estrangeiro" (Berman, 2002, p. 16), pois ela é essencialmente "abertura, diálogo, mestiçagem, descentralização" (Ibid., p. 17).

Embora as tendências deformadoras sejam um conjunto de ferramentas para a análise de traduções literárias normalmente etnocêntricas, tais deformações, por serem inerentes à tradução, dependendo do projeto e do modo como o tradutor as aborda, podem auxiliar na realização de uma tradução nãoetnocêntrica. Assim, uma das treze deformações foi por mim considerada um recurso viável para a concretização de um projeto de tradução estrangeirizante de uma obra literária em versos: trata-se da tendência ao enobrecimento. Berman explica o enobrecimento como a presença excessiva do elemento estético a fim de chegar a traduções "mais belas" do que o original (1985/ 1999, p. 57). Entretanto, recorrer a certo grau de rebuscamento estético não significa, necessariamente, ter o objetivo de escrever um texto mais belo do que o original. No caso da tradução do The tragical history, tornar a presença do elemento estético mais frequente, porém não excessiva, via arcaísmos e/ ou palavras, expressões ou construções sintáticas não tão correntes no uso do português, tem a intenção de demarcar a distância temporal do texto original e propiciar certa sensação de estranheza no leitor, uma vez que o enobrecimento pode tornar a linguagem da tradução mais distante daquela normalmente utilizada por ele.

Berman nos fala ainda sobre a ética da tradução (Ibid.) ou ato de preservar a identidade do texto estrangeiro em uma cultura que não lhe é familiar, recebendo o Outro sem transformá-lo em algo diferente daquilo que ele realmente é. A ética admite a tradução como um lugar de intercâmbio linguísticocultural, onde ocorre um diálogo entre dois textos e o estrangeiro, o estranho, manifesta-se. Dessa maneira, a não negação sistemática da estranheza da obra estrangeira caracteriza a noção de fidelidade definida pela ética da tradução. Eis o ponto de convergência entre a ideologia de Berman e a de Schleiermacher. Ser ético ao realizar uma tradução é criar condições favoráveis para que o estrangeiro se revele na cultura doméstica.

No intuito de deixar no texto traduzido de Marlowe traços que evidenciassem sua condição de tradução e, consequentemente, expressassem a presença do tradutor, algumas considerações feitas por Lawrence Venuti foram tomadas como fundamentais.

Em The translator's invisibility: a history of translation (1995), Venuti nos fala que a relação da tradução com os fatores sociais e culturais existentes onde ela é produzida e lida aponta para uma "violência etnocêntrica" que, em parte, é inerente à tradução, uma vez que esta "is the forcible replacement of the linguistic and cultural difference of the foreign text with a text that will be intel-

Tal publicação ocorreu em 2007, pela editora 7Letras (Rio de Janeiro), sob o título "A tradução e a letra ou o albergue do longínquo".

12 "um todo sistemático, cujo fim é a destruição, não menos sistemática, da letra dos originais, somente em benefício do sentido e da bela forma".

13 "que desviam a tradução de seu verdadeiro objetivo". 
ligible to the target-language reader"14 (Venuti, 1995, p. 18). Mas mesmo a porção de etnocentrismo intrínseca ao processo tradutório pode, e deve, ser reduzida quando se objetiva marcar a distância cultural e temporal entre original e tradução, contribuir para o enriquecimento da cultura nacional e tornar a posição do tradutor aparente.

Com base nas declarações de Friedrich Schleiermacher (1813), Venuti considera a estrangeirização, defendida pelo alemão, uma maneira de conter a violência etnocêntrica da tradução, o que, segundo ele, é altamente desejável no atual cenário mundial, podendo representar uma forma de resistência à hegemonia das nações de língua inglesa e às trocas culturais desiguais que aquelas impõem a outros países. "Foreignizing translation in English can be a form of resistance against ethnocentrism and racism, cultural narcissism and imperialism, in the interests of democratic geopolitical relations"15 (Venuti, 1995, p. 20).

Não apenas na língua inglesa, mas também em qualquer língua colonial ou nativa, a "tradução é altamente eficaz em exacerbar as tensões" desses discursos, pois o "movimento entre as línguas coloniais e nativas pode reconfigurar as hierarquias culturais e políticas entre elas, desestabilizando o processo de formação de identidade, a imitação dos valores hegemônicos na qual a colonização se baseia" (Venuti, 2002, p. 321).

Como estratégias de estrangeirização, Venuti cita, dentre outros exemplos, o uso de arcaísmos e de uma métrica diferente daquela normalmente usada em traduções de textos poéticos canônicos em dada cultura (Venuti, 1995, p. 122-3; 197) e, também, o uso de resíduos linguísticos, ou seja, jargões, gírias, dialetos, clichês, etc. Tais resíduos são constituídos pelas chamadas variáveis menores, sempre dominadas por uma "forma maior", uma vez que uma língua é sempre "um lugar de relação de poder" (Ibid., p. 24-25). Assim, o resíduo de uma língua maior torna-se capaz de indicar onde esta é estrangeira em si mesma. A partir de tal noção, uma tradução pode apresentar-se como a expressão estrangeira do outro dentro da cultura doméstica, estabelecendo e demonstrando ao seu leitor as diferenças inter e intraculturais.

Traçado o caminho teórico tradutológico, fez-se necessário dar passagem à teoria do teatro e estabelecer sua relação com a tradução. Para tanto, dois trabalhos foram essenciais: o de Patrice Pavis (1995) e o de José Roberto O'Shea (2002).

Patrice Pavis, ao falar sobre tradução de textos teatrais, considera a realização desse ofício a partir da "situação de enunciação", definida como o momento de encenação de um texto dramático por um ator, ou um grupo de atores, diante de um público que recebe, simultaneamente, texto e mise en scène, em lugar e tempo específicos (Pavis, 1995, p. 136). O tradutor deve traduzir ciente de que seu texto, possivelmente, terá os atores como veículo de transmissão e, por isso, não se pode traduzir (como em qualquer outra tradução) apenas o material linguístico, principalmente porque existem, na relação original-tradução, a comunicação e o contraste entre culturas, códigos e situações de enunciação distintas. "The translator and the text of the translation are situated at the intersec-

\footnotetext{
14 “é a substituição forçada da diferença linguística e cultural do texto estrangeiro por um texto que será inteligível ao leitor da língua alvo”. Minha tradução.

15 “A tradução estrangeirizante, em inglês, pode ser uma forma de resistência ao etnocentrismo e ao racismo, ao narcisismo cultural e ao imperialismo, nos interesses de relações geopolíticas democráticas". Minha tradução.
} 
tion of two sets [the original situation of enunciation and the intended one] to which they belong in differing degrees" "16 (Ibid.) [grifo meu]. Tradutor e tradução serão, então, o elo de ligação entre dois "cenários", duas culturas ou duas situações de enunciação diferentes.

A obra literária "concretiza-se" - termo usado por Pavis, segundo Roman Ingarden (1931) - por meio da leitura do original ou da tradução, e, ainda, de sua encenação. No entanto, desde a sua constituição até a sua recepção, a obra - e a tradução - passa por uma gama de transformações, pois a "leitura [...] configura um processo criativo no qual o leitor/ tradutor, a um só tempo, "concretiza" algo que, de certa forma, ele encontra no texto e modifica algo já elaborado pelo autor" (O'Shea, 2002, p. 33). Tais transformações são abordadas por Pavis (1995, p. 138-141) como uma "série de concretizações", iniciada pelo texto original $\left(\mathrm{T}_{0}\right)$, passando pela concretização textual $\left(\mathrm{T}_{1}\right)$, pela concretização dramatúrgica $\left(T_{2}\right)$ e cênica $\left(T_{3}\right)$, chegando até o momento da recepção $\left(T_{4}\right)$.

Ao refletir sobre sua experiência como tradutor de textos dramáticos e a relação existente entre o drama traduzido e o seu original, O'Shea propõe que "as convenções da dramaturgia valem tanto para textos originais quanto para textos traduzidos" (2002, p. 32). A partir disso a tradução é por ele definida "como um processo hermenêutico e criativo, envolvendo uma gama de atividades complexas e não estanques: leitura, releitura, pesquisa, criação, experimentação, adaptação, escritura, revisão e re-escritura", estando estas também presentes no "processo original de composição dramatúrgica" (Ibid.). Desse modo, se o processo de tradução e o de escritura de uma obra para teatro envolvem os mesmos tipos de atividades, não há razão para privilegiarmos apenas as questões ligadas à dramaturgia e ignorarmos aquelas referentes à tradução.

Com base na tipologia proposta por Pavis, na qual "a série de concretizações, ou traduções intermediárias, caracterizam o processo de apropriação da cultura de partida por parte da cultura de chegada" (Ibid., p. 41), O'Shea conclui que a "especificidade do texto dramático se aplica tanto à composição quanto à tradução"; não havendo, portanto, motivos para que o texto dramático original seja posto "em posição hierarquicamente superior ao traduzido" (Ibid., p. 42). Para ele, "já é tempo de se aceitar o texto dramático traduzido, em toda a sua especificidade, em sua nova inscrição cultural, como algo que, de fato, ele constitui: um novo original" (Ibid.). Se a tradução constitui-se como um novo original, não seria exagero afirmar que o tradutor encontra-se, assim, na posição de um novo autor.

A existência assumida e aceita de uma tradução e de seu tradutor; e as posições paralelas e complementares ocupadas pelo original e sua tradução, bem como pelo autor e pelo tradutor, só vêm ratificar as palavras dos teóricos da tradução expostas anteriormente. As considerações de Pavis, juntamente com as reflexões de O'Shea, em interface com os Estudos da Tradução, complementam e solidificam os alicerces do projeto de tradução do drama do Dr. Faustus.

\footnotetext{
${ }^{16}$ Tradução ao inglês de Loren Kruger. "O tradutor e o texto da tradução estão situados na intersecção de dois contextos [a situação de enunciação original e pretendida] aos quais eles pertencem em diferentes graus". Tradução ao português de minha autoria.
} 


\section{As teorias e a prática tradutória}

Todo ato tradutório pressupõe a existência de uma teoria que se reflete na tradução, de modo discreto, talvez imperceptível, e, muitas vezes, sem a intenção do tradutor. Isso ocorre porque a simples reflexão sobre quais escolhas serão mais adequadas às várias situações de tradução gera, em cada tradutor, um modo próprio de realizar o seu ofício. Além de suas reflexões, o tradutor pode, ainda, assumir uma afiliação a um modelo teórico já estabelecido, buscando fazer uso dos conceitos existentes nesse modelo, no momento da tradução. Temos, então, a utilização consciente de pressupostos teóricos na prática tradutória.

Tendo em vista o objetivo geral de minha pesquisa, ou seja, verificar em que medida certas teorias da tradução podem funcionar como base para a prática tradutória, apresento, aqui, alguns exemplos extraídos da tradução do $D r$. Faustus, juntamente com comentários tecidos a partir da utilização dos pressupostos teóricos aplicados ao ato tradutório da referida obra. Ressalto tratar-se de poucos exemplos, mas que já são capazes de transmitir uma ideia de como a pesquisa foi realizada e como se estrutura a dissertação.

Segundo Schleiermacher, realizar uma tradução não-etnocêntrica de um texto literário faz-se possível se a língua e a cultura alvo oferecerem condições favoráveis, isto é, "que a compreensão de obras estrangeiras seja um estado conhecido e almejado, e que à própria língua vernácula seja concedida certa flexibilidade." (1813/ 2011, p. 44). Em nosso país, esses dois fatores são factíveis. Basta que entremos em qualquer livraria e olhemos as obras expostas para percebermos que a maior parte dos títulos à venda são traduções, o que demonstra o interesse de nosso povo em conhecer culturas distintas.

A característica "flexibilidade" é algo inerente à maior parte das línguas. Em sua maioria, elas não possuem uma formação homogênea e sempre ocorrem empréstimos, e ao tratarmos da língua portuguesa falada no Brasil, um país composto por uma enorme diversidade étnica, tal característica acentua-se. $\mathrm{O}$ contato multilateral com o estrangeiro, proporcionado por tal flexibilidade, permite o desenvolvimento e fortalecimento da língua e pode ser considerado, nos termos de Meschonnic (1973), um descentramento, um diálogo entre duas culturas distintas capaz de conferir ao tradutor e à tradução não apenas o papel de mediadores, mas também uma importante função social por contribuírem para o enriquecimento da língua-cultura materna. É aqui, nesse diálogo intercultural, que fecunda o próprio por intermédio do estrangeiro, que se encontra a "pura meta" da tradução (Berman, 2002, p. 16).

O projeto de tradução estrangeirizante do texto de Marlowe começou a ganhar forma, na prática, quando os nomes próprios existentes na obra foram considerados elementos capazes de marcar sua distância cultural, deixando à mostra seu caráter estrangeiro. Por essa razão, em sua maioria, não foram traduzidos, mesmo quando possuíam equivalentes em português. Para exemplificar, cito Thrasimene, Faustus, Mephostophilis, Cornelius e Charles, cujos equivalentes são Trasímeno, Fausto, Mefisto ou Mefistófeles, Cornélio e Carlos, respectivamente. No caso do nome do rei da Espanha, foi considerado que, no texto de Marlowe, ele foi traduzido de "Felipe" para Philip, fato que caracteriza, no próprio original, uma domesticação ou etnocentrismo. Tendo em vista que a tradução de The tragical history baseia-se em um projeto que se opõe ao etnocentrismo, a grafia original espanhola foi mantida. 
Valdes: (...) And from America the golden fleece

That yearly stuffs old Philip's treasury

If learned Faustus will be resolute.

Valdes: (...) E, da América, o velocino de ouro

Que abarrota o tesouro do velho Felipe,

Se o douto Faustus resoluto estiver.

(Ato I, cena 1)

Os substantivos que designam unidade monetária como penny, e o seu plural pence, e farthing não foram traduzidos ou convertidos a nenhuma unidade monetária utilizada, nesse momento ou no passado, no Brasil. Ambos constituem um forte marcador cultural e também temporal, no caso de farthing, que é uma antiga moeda inglesa, e ressaltam a origem da obra. Entretanto, no caso de guilder, antiga moeda holandesa, optei por sua tradução, florim, pois esta, ao ser pouco, ou raramente, utilizada em português, faz parte de um grupo de "variáveis menores" ou formas linguísticas usadas especificamente por determinadas comunidades culturais dentro de uma língua padrão como, por exemplo, os jargões e os dialetos. Venuti (2002, p. 25-26), com base no trabalho de Lacercle (1990), chama essas variáveis de "resíduo", que, ao ser liberado, "indica onde a língua é estrangeira em si mesma". Assim, a tentativa de transmitir o caráter estrangeiro do texto de Marlowe em minha tradução realiza-se não apenas a partir das palavras inglesas deixadas sem tradução, mas também a partir da liberação de alguns "resíduos" oferecidos pela língua portuguesa, sejam eles expressos em uma única palavra ou em uma expressão.

Como já foi exposto, uma das treze tendências deformadoras responsáveis pela "destruição" da letra dos originais "em benefício do sentido e da bela forma" (Berman, 1985/ 1999, p. 52) foi considerada uma forma de estrangeirização. Refiro-me à tendência ao enobrecimento, definida como a presença excessiva do elemento estético a fim de se chegar a traduções "mais belas" do que o original (Ibid., p. 57). Ao utilizar o enobrecimento de forma proposital na tradução do Faustus, o meu objetivo foi salientar a distância temporal da obra e provocar uma sensação de estranheza em meu leitor via utilização de uma linguagem não tão corrente no português. Para tanto, recorri ao uso de arcaísmos e construções sintáticas mais formais ou mais elaboradas. Assim, é comum encontrarmos, na tradução:

○ arcaísmos como "mercador" e "estalajadeira", ou palavras cujo registro é mais formal e elevado, como "ardiloso", "exaurir", "empíreo" e "tépido";

- ênclises e mesóclises, como em "Diga-lhes fervorosamente que me visitem" e "Tornar-te-ás mais sábio do que eu", no original, "Request them earnestly to visit me" e "And then wilt thou be perfecter than I", respectivamente;

○ inversões, como em "E com essa visão, tu a mim agradas mais" e "Oh, possam essas pálpebras não mais se fecharem/ Até eu, com minha espada, ter tal feiticeiro morto", no original "And in this sight thou better pleasest me" e "Oh, may these eyelids never close again/ Till with my sword I have that conjuror slain." 
Considerando a proposta de Venuti, podemos classificar o enobrecimento apontado por Berman como uma espécie de resíduo. Assim, de acordo com a noção de resíduo, o rebuscamento vocabular, o uso de arcaísmos e anástrofes em uma tradução podem evitar que o texto resultante seja encarado como uma domesticação na língua alvo, já que tais elementos são capazes de mostrar onde a língua é estrangeira em si mesma. O tradutor, porém, há que tomar cuidado com os excessos, pois isso pode transformar o texto em um discurso demasiado empolado, cansativo e, o pior de tudo, incompreensível.

$\mathrm{Na}$ tentativa de "guiar" o leitor em direção ao reconhecimento do tradutor e de seu papel autoral, algumas notas presentes na tradução do Dr. Faustus trazem a indicação de que, naquele trecho, a decisão tomada tem como objetivo deixar mais à mostra a figura daquele que traduz. Tais notas trazem informações referentes tanto ao processo tradutório e à utilização das teorias de tradução nesse processo, quanto a explanações sobre questões históricas e mitológicas presentes na obra de Marlowe, além de considerações acerca de outras edições e traduções da peça.

A tradução de The tragical history foi realizada com foco no caráter literário do texto de Marlowe, e não no cênico, o que, segundo Bassnett-McGuire (1985, p. 90), é a forma mais comum de traduzir textos teatrais. No entanto, tendo em vista que no momento da leitura de um texto dramático há, nas palavras de Pavis (1995), uma "situação de enunciação virtual" de tal texto, uma concretização cênica virtual na mente do leitor, e que o trabalho do tradutor deve ser direcionado a uma situação de enunciação a ser concretizada, questões referentes à performance do Dr. Faustus foram consideradas ao longo da tradução, e algumas sugestões a esse respeito fazem-se presentes em minhas anotações. Duas delas encontram-se no ato I, cena 4, quando Wagner tenta convencer o palhaço a servi-lo.

Wagner: Sirrah, hast thou no comings in?

Clown: Yes, and goings out too, you may see, sir.

Wagner: Alas, poor slave. See how poverty jests in his nakedness. I know the villain's out of service and so hungry that I know he would give his soul to the devil for a shoulder of mutton though it were blood-raw.

(Grifos meus)

A expressão comings in significa "salário, pagamento, renda, algo a ser recebido". Entretanto, devido a sua resposta, Yes, and goings out too (...), o palhaço parece ter compreendido a expressão usada por Wagner de modo literal (Boas, 1966, p. 74), ou seja, como se Wagner estivesse lhe perguntando se tinha algo a "entrar" e não a "receber", e, por essa razão, o palhaço diz que também tem goings out, ou "o que sair". Portanto, se o palhaço compreendeu a expressão de Wagner de maneira literal, optei por traduzi-la também de modo literal, estando a referência a dinheiro implícita na fala. Vejamos:

Wagner: Criado, tu não tens o que entrar?

Palhaço: Sim, e também o que sair, como podeis ver, senhor.

Wagner: Pobre serviçal. Veja como a pobreza zomba de tua nudez. Sei que o miserável está sem serviço e tão faminto que daria sua alma ao demônio em troca de um pernil de carneiro, ainda que cru em sangue. (Grifos meus) 
Na hipótese de uma encenação da peça, o que sugiro é que o ator no papel de Wagner, ao perguntar "tu não tens o que entrar?", indique a referência a dinheiro contida na expressão inglesa fazendo o típico gesto com os dedos, no qual o polegar "coça" o indicador, por exemplo. Sabendo que "a pobreza zomba" da nudez do palhaço, pode-se dizer que o que "sai" dele são os farrapos de sua roupa, que, de tão velha, não resiste sequer a seu toque. Tendo em mente essa interpretação, minha segunda sugestão é que o ator no papel do palhaço complemente a fala "Sim, e também o que sair, como podeis ver, senhor", arrancando e oferecendo um pedaço de suas pobres e surradas vestes a Wagner.

Traduzir para o teatro é mais do que traduzir somente as palavras contidas no original; é fazer com que as palavras traduzidas sejam capazes de transmitir, além da carga cultural, a imagem e o sentido propostos no original. Para isso, o tradutor não pode traduzir apenas a partir da experiência do autor ao escrever a obra, mas também a partir de sua experiência ao lê-la.

\section{Conclusão}

De maneira geral, utilizar uma ou várias teorias para nortear uma tradução torna-se eficaz na medida em que fornece ao tradutor um espaço seguro, calcado em princípios éticos, ideológicos e filosóficos, para a realização do seu ofício. Entretanto, embora as teorias aqui abordadas apresentem-se fundamentadas em uma longa análise e estudo sobre traduções e o ato de traduzir de alguns tradutores e dos próprios teóricos, e forneçam justificativas para as escolhas do tradutor do texto de Marlowe, elas limitam o seu agir, por vezes restringindo a sua atuação à utilização de algumas estratégias.

O conceito de resíduo, por exemplo, definido por Venuti (2002, p. 2425) como as variáveis menores de uma língua capazes de liberar a porção de estrangeiro existente nessa língua, funciona como uma estratégia estrangeirizante se não considerarmos os arcaísmos, dialetos, jargões, palavras e expressões $a d$ hoc, etc. generalizadamente como tal, já que dificilmente encontraremos, em nossa própria língua, uma só palavra que seja "estranha", estrangeira, a todos os leitores. O resíduo pode ser considerado uma espécie de marcador de distância temporal ou, ainda, uma variante capaz de tornar o texto traduzido mais, ou menos, formal e/ou elegante, dependendo do padrão linguístico adotado.

Considerar uma métrica diferenciada daquela normalmente utilizada para a tradução de certos tipos de textos - nesse caso, um texto dramático renascentista escrito em versos - também proposta por Venuti (1995, p. 122-123) como uma estratégia de estrangeirização, cumpre esse papel apenas no aspecto de impor resistência aos padrões literários canônicos. Contudo, essa estratégia não tem muito valor quando se trata da transmissão dos aspectos literários estrangeiros, pois, usar uma métrica semelhante à do original a fim de manter, na tradução, um ritmo parecido, poderia proporcionar uma característica estrangeira a mais à cultura receptora da tradução: a sonoridade peculiar aos textos escritos durante a renascença inglesa.

Após todo o processo de estudo teórico, sua aplicação prática e considerações a respeito dessa relação, percebemos que as estratégias mais suscetíveis de conferir o status de estrangeiro a uma tradução são a não-conversão de unidades de medidas e unidades monetárias, a não-tradução de substantivos próprios, podendo excetuar-se aqueles cuja tradução já se encontra arraigada na 
cultura-alvo, e a não-adaptação de elementos próprios da cultura de partida à cultura doméstica, como, por exemplo, substituir um provérbio ou uma cantiga folclórica inglesa por uma cantiga ou provérbio tipicamente brasileiro e com a mesma carga semântica. A utilização de arcaísmos, palavras cujo registro é formal ou elevado, anástrofes e outros recursos estilísticos me parecem ser melhor considerados como marcadores de distanciamento temporal e elementos capazes de auxiliar na escrita de uma tradução mais próxima ou não da realidade linguística de seus leitores. É esse distanciamento temporal e linguístico, capaz de marcar a existência de um texto portador de traços culturais distintos e anteriores à tradução, que a caracterizará como estrangeirizante.

Wanessa Gonçalves Silva

s.wanessa@gmail.com

Tradutora e intérprete, Mestre, Universidade Federal da Grande Dourados 


\section{Referências bibliográficas}

BASSNETT-McGuire, Susan. Ways through the labyrinth. Strategies and methods for translating theatre texts. In: The manipulation of literature: studies in literary translation. New York: St. Martin's Press, 1985.

Berman, Antoine. Pour une critique des traductions: John Donne. Paris: Gallimard, 1995.

. La traduction et la lettre ou l'auberge du lointain. Paris: Éditions du Seuil, 1999.

. A tradução e a letra ou o albergue do longínquo. Trad. Marie-Hélène C. Torres \& Mauri Furlan \& Andréia Guerini. Rio de Janeiro: 7Letras, 2007.

. A prova do estrangeiro: cultura e tradução na Alemanha romântica. Trad. Maria Emília Pereira Chanut. Bauru, SP: EDUSC, 2002.

BoAS, Frederick Samuel. Introduction and Appendices. In: Christopher Marlowe. The tragical history of Doctor Faustus. New York: Gordian, 1966.

MAAR, Alexandre Weller. Doutor Faustus sobe aos palcos: uma história do trágico; pensamentos e modernidade na renascença de Christopher Marlowe, Londres, 1604. 2003. 150 f. Monografia (Graduação) - Curso de História, Universidade do Estado de Santa Catarina, Florianópolis.

MARlowe, Christopher. The tragical history of Doctor Faustus. In: Christopher Marlowe: the complete plays. Edited by J.B. Steane. England: Penguin Books, 1969.

. Doutor Fausto. Trad. João Ferreira Duarte \& Valdemar Azevedo Ferreira. Tito Lyon de Castro (ed.). Portugal: Publicações Europa-América, 2003.

Meschonnic, Henri. Pour la poétique II. Épistémologie de l'écriture - Poétique de la traduction. Paris: Gallimard, 1973.

O’SHEA, José Roberto. Performance e inserção cultural: Anthony and Cleopatra e Cymbeline, King of Britain em português. In: Willian Shakespeare. Cymbeline, Rei da Britânia. São Paulo: Iluminuras, 2002.

PAVIS, Patrice. Toward specifying theatre translation. In: Theatre at the crossroads of culture. Translated by Loren Kruger. London/New York: Routledge, 1995.

SCHLEIERMACHER, Friedrich. Dos diferentes métodos de traduzir. Trad. Mauri Furlan. In: Scientia Traductionis, no 9. Florianópolis: UFSC, 2011. p.0370. 